\title{
Enfermedades virales emergentes en ganado de leche de América Latina
}

\section{Emerging viral diseases in Latin-American dairy cattle}

\author{
Enfermidades virais emergentes em bovinos leiteiros \\ na América Latina
}

Diana S. Vargas ${ }^{1 *}$, Agustín Góngora-Orjuela ${ }^{2}$, Jairo Jaime Correa ${ }^{3 *}$

1* $^{*}$ MV, MSc
MV, MSc, Dr. Sci. Grupo de investigación en Reproducción y Genética Animal. Universidad de los Llanos.
$3^{*}$ MV, MSc, PhD. Grupo de investigación en Microbiología y Epidemiología. Universidad Nacional de Colombia.
Sede Bogotá. Email: susandvb@hotmail.com

Recibido: agosto 23 de $2012 \quad$ Aceptado: noviembre 13 de 2012

\begin{abstract}
Resumen
El propósito de este artículo es la actualización sobre algunas enfermedades virales de más reciente descubrimiento o nuevas variantes virales que afectan la producción de ganado de leche con especial referencia a América Latina. La alta demanda de leche y sus derivados por una población humana, en constante crecimiento, podría ocasionar a corto plazo un desabastecimiento, incrementando los índices de desnutrición humana en muchos países. Se requiere entonces, avanzar en los aspectos epidemiológicos, de diagnóstico y control de estas enfermedades con el objeto de limitar las pérdidas económicas ocasionadas a la industria láctea.
\end{abstract}

Palabras clave: América latina, ganado lechero, enfermedades emergentes.

\begin{abstract}
This paper was aimed at updating readers regarding some recently discovered viral diseases or new viral variants affecting dairy-cattle production, with special reference to Latin-America. A growing human population's high demand for milk and its derivatives around the world may lead to as hort-term shortage, thereby increasing human malnutrition indices in many countries. Progress must thus be made in epidemiology, diagnosis and monitoring to limit the dairy industry's financial losses caused by these diseases.
\end{abstract}

Key words: Latin-America, dairy cattle, emerging disease.

\section{Resumo}

O propósito do artigo é a atualização sobre algumas doenças virais de recente descoberta ou novas variantes virais que afetam a produção de gado leiteiro com especial referência na América Latina. A alta procura do leite e, seus derivados pela população humana em constante crescimento poderiam ocasionar no curto prazo desabastecimento, incrementando os índices de desnutrição humana em muitos países. Requer-se então avançar nos aspectos epidemiológicos, de diagnostico e controle destas doenças com o objetivo de limitar as perdas econômicas ocasionada na indústria láctea.

Palavras-chave: América latina, gado leiteiro, doenças emergentes. 


\section{Introducción}

Paralelo al gran avance genético obtenido en los últimos años en los aspectos productivos del ganado de leche, han surgido agentes virales emergentes y reemergentes que ponen en riesgo la salud animal, la productividad y la rentabilidad de la empresa ganadera; con el ánimo de evitar controversia, es necesario aclarar el concepto de virus emergente. Como lo señala Rodas (2002), el término emergente podría significar algo nuevo, por lo que valdría reflexionar si realmente se están descubriendo nuevos virus o por el contrario, solo se están detectando por primera vez debido al avance en las técnicas diagnósticas. De hecho, al revisar la historia del descubrimiento de cada uno de estos agentes, es posible determinar si fueron originalmente reportados por primera vez en países de América Latina o si, por el contrario, fueron llevados allí mediante diferentes formas de comercio como la importación de animales, de semen, de embriones y de otras no establecidas plenamente.

En esencia, la vaca de leche es más susceptible a padecer cualquier infección, incluidas las infecciones virales en razón de las altas demandas metabólicas ocasionadas por los sistemas de producción cada vez más intensivos, lo que ocasiona problemas clínicos como mastitis, laminitis, abortos, muerte embrionaria e infertilidad (Walsh et al., 2011). No obstante, se conoce que las mayores pérdidas económicas son ocasionadas por los problemas subclínicos.

\section{Producción láctea dentro del contexto global y de América Latina}

La producción mundial de leche ha tenido un incremento sostenido durante los últimos años. En el periodo comprendido entre 1992-2006 aumentó de 460 a 550 millones de toneladas, que representa un aumento en la tasa acumulativa de $1.27 \%$ (Galeto, 2008). Una proyección de la producción mundial de leche para el 2011 sugiere que podría alcanzar los 724 miIlones de toneladas, lo cual representa un aumento del 2\% comparado con el año 2010 (Fao, 2004). Este aumento en la oferta de leche ha sido atribuido en gran medida a los países que han presentado un rápido desarrollo de la producción agrícola como Argentina, Brasil, China e India al igual que a los mayores exportadores de productos lácteos como la Unión Europea, Nueva Zelanda y Estados Unidos; favorecida a la vez por la mayor demanda de los países asiáticos. El principal productor de leche es EU, seguido de india, Rusia y Alemania; Colombia ocupa el puesto 21 dentro del contexto mundial (Ortega, 2007).
En otros países de América Latina como Colombia y Ecuador se ha incrementado la producción de leche y ahora son auto sostenibles, mientras en el Perú a partir de 1992 se presenta un aumento del 5\% anual. Colombia con una producción de 6.500 millones de toneladas por año, ocupa el cuarto lugar dentro de los países productores de leche en America Latina, solo superado por Brasil, México y Argentina (Proexport, 2012)

En cuanto al consumo de leche por los diferentes países, intervienen factores de tipo cultural y el nivel de ingresos de la población. En Europa y América del norte (Canadá y USA) se tienen los mayores consumos per cápita, estimados entre 200-300 Litros/año. En América Latina y el Caribe, el consumo puede oscilar entre 40-60 Litros/año. Para los países centroamericanos, Uruguay y Argentina el consumo per cápita oscila entre 200-250 Litros/año. Otros países de América del sur, como Brasil y Chile reportaron consumos promedio de 140 litros/año (Galeto, 2008).

En la actualidad, las predicciones sobre la producción de leche indican que esta pasará en términos de volumen de los países con altos costos operativos a aquellos con menores costos. Lo anterior favorecerá el aumento de la producción en los países de América Latina y el Caribe, lo que podrían alcanzar un incremento global de 19 millones de toneladas (Fao, 2004). Lo anterior debe ir ligado a un avance simultáneo en el conocimiento y control de los principales limitantes de la industria láctea, incluidos aquellos factores sanitarios, entre ellos los agentes infecciosos de origen viral motivo de la presente revisión. Entre estos agentes virales que emergen como nuevos actores se encuentran el Herpesvirus bovino 5 y el virus de inmunodeficiencia bovina y virus que reemergen con nuevas cepas o variantes como el virus de la Diarrea viral Bovina y el rotavirus Bovino. A continuación, se revisa la evolución histórica y las características más importantes de estas infecciones virales con especial referencia a Colombia y America Latina.

\section{Virus de la Diarrea Viral Bovina (BVDV)}

Es un miembro del género pestivirus de la familia Flaviviridae. El genoma de VDVB es un ARN con polaridad positiva, no segmentado y de banda sencilla, posee una longitud de 12.5 kilobases (Hamers et al., 2001). El virus tiene forma esférica con un diámetro entre 40 a $60 \mathrm{~nm}$. Está constituido por una cápside icosahédri$\mathrm{ca}$, rodeado de una envoltura lipoprotéica tomada de la membrana citoplasmática (Mettenleiter y Sobrino, 2008). 
El virus de la Diarrea Viral Bovina (BVDV) fué reconocido por primera vez en los Estados Unidos por Olafson et al. (1946), en hatos con síndrome agudo caracterizado por fiebre, diarrea, anorexia y tos. Ramsay y Chivers (1953), describieron una enfermedad esporádica caracterizada por diarrea profusa, emaciación, ulceraciones en la mucosa del tracto alimenticio y una mortalidad del $100 \%$.

Posteriormente, se determinó que los dos síndromes eran provocados por el mismo virus (Moenning, 1993). A finales de los 60's se describieron los dos biotipos del virus: el citopático (cp) y el no citopático (ncp), por su habilidad de causar efecto citopático y muerte celular en cultivos celulares in vitro. El biotipo cp induce destrucción masiva celular mediante la formación de vacuolas citoplasmáticas lo que ocasiona la muerte de las células pocos días después de la infección, mientras que el biotipo ncp no induce ningún efecto aparente en cultivo (Brock, 2004; Vargas et al., 2010). El biotipo ncp es el único que puede ocasionar infección persistente en el feto cuando infecta a la madre durante la gestación, lo que ocasiona el nacimiento de un animal aparentemente saludable pero que permanece infectado de por vida, por lo tanto, es el mayor excretor de virus al medio (Peterhans et al., 2010)

Los avances en secuenciación genética a finales de los ochenta permitieron establecer dos genotipos: el 1 y 2, caracterizados por diferencias en la región 5' UTR y en la región que codifica para la proteína E2 principalmente. El genotipo 2, el cual surgió en Norte América y Canadá se correlaciona con sintomatología hemorrágica y alta mortalidad (Ridpath, 2010). De esta manera, en la naturaleza existen 2 biotipos y 2 genotipos. Adicionalmente, cada genotipo presenta subgenotipos los cuales muestran una homología entre sí del 80 al 85\%.

En la actualidad se han reportado en la literatura 11 subgenotipos de BVDV tipo 1 (a-j) y 2 subgenotipos del BVDV- 2 ( $a$ y b). Recientemente, algunos aislamientos a partir de suero fetal bovino contaminado de un búfalo persistentemente infectado (PI) en Brasil y de jirafas en Kenia llevaron a sugerir la presencia de un tercer genotipo denominado BVDV3 (Ridpath, 2010).

Estos nuevos aislamientos son muy similares a los genotipo 1 y 2 del BVDV de acuerdo a su homología con las regiones del genoma: 5'UTR, Npro y E2 (Liu et al., 2009; Vargas et al., 2010). En Colombia, los primeros reportes de la enfermedad surgieron en 1975, tras el ingreso al país de terneros enfermos importados desde Holanda (Borda, 1975). El primer aislamiento viral se realizo en 1981 a partir de una ternera muerta por parasitismo y complicaciones respiratorias (Gallego et al., 1987). Diferentes estudios serológicos evidencian una prevalencia entre $45-90 \%$ (Vargas et al., 2009). Para la fecha se desconoce en el país la presencia del genotipo 2 y del genotipo 3, así como también de los diferentes subgenotipos que podrían estar circulando, pero estos se han aislado en otros países de América Latina como Argentina y Brasil (Flores et al, 2002; Vargas et al., 2009). Debido a la gran variedad de cepas del BVDV y a la emergencia cada vez de nuevas variantes, la caracterización de estas es de gran importancia en los estudios epidemiológicos con el fin de mejorar el diagnóstico y desarrollar mejores alternativas en el control de la enfermedad en los países latinoamericanos (Flores et al., 2002; Vargas et al., 2010).

Las pérdidas económicas producidas por el virus DVB se han asociado principalmente a problemas reproductivos como abortos, aumento de los días abiertos, baja calidad de semen de los reproductores, disminución en la producción y costo del tratamiento de los animales enfermos (Valle et al., 2005). La cuantificación de las pérdidas económicas frente a la infección con BVDV en hatos lecheros en Europa se ha calculado entre 13-160 € por vaca al año dependiendo del tipo de presentación de la enfermedad (Fourichon, 2005). Las pérdidas se pueden incrementar cuando el BVDV se combina con otros patógenos como los del complejo respiratorio bovino (Gunn et al., 2005). En Dinamarca, las pérdidas económicas atribuidas al BVDV en 1999 se estimaron en 20 millones de dólares (Houe, 1999), mientras en Nueva Zelanda alcanzaron los 44.5 millones de dólares sobre un estimativo de $14.6 \%$ de fincas infectadas (Heuer et al., 2007). En Colombia, no se han individualizado las perdidas para BVDV sin embargo se ha establecido en la ganadería bovina pérdidas generales para todas las enfermedades reproductivas de 44.000 millones de pesos, donde el BVDV juega un papel importante en el desarrollo de las mismas (Castañeda, 2004).

La vacunación se ha implementado como medida de control de la enfermedad. Entre las vacunas disponibles en el mercado nacional e internacional se encuentran las vacunas inactivas y las de virus vivo modificado (VLM). En su mayoría estas vacunas vienen en presentación polivalente junto con otros antígenos virales o bacterianos. En la última década se encuentran en desarrollo las vacunas recombinantes empleando las secuencias más inmunogénicas del virus como la proteína E2 insertando estas secuencias en vectores virales (adenovirus, herpesvirus entre otros) o no virales como plásmidos (Nobiron et al., 2003). En países como Colombia, esta tecnología se comenzó a desarrollar a partir del 2007 y actualmente se viene probando una vacuna recombinante para el virus de la 
DVB por el grupo de investigación de microbiología y epidemiologia de la Universidad Nacional de Colombia (Vargas et al., 2011).

Algunos países, particularmente los escandinavos, han instaurado programas de erradicación de la enfermedad, basados en el control sistemático sin vacunación y control sistemático con vacunación (Stahl et al., 2005; Uttenthal et al., 2005; Valle et al., 2005). Igual estrategia ha adoptado suiza para erradicar la enfermedad, la cual incluye además la identificación de reactores positivos en especies silvestres (Casaubon et al., 2012). Contrariamente en Norteamérica y Suramérica la prevalencia es alta y todavía se mantiene como uno de los virus que ocasiona las mayores pérdidas económicas en la industria lechera. En razón a su importancia para la salud animal a nivel global, la organización mundial de salud animal (OIE) en el 2007 incluyó este virus dentro de la lista de enfermedades de reporte obligatorio (Ridpath, 2010).

\section{Herpes virus bovino tipo 5 -HVB5}

Es un miembro del género Varicellovirus de la familia Herpesviridae al igual que el Herpesvirus Bovino 1 (BoHV-1) (Campos et al., 2009). El genoma de HVB5 es un ADN de doble cadena.

El herpesvirus virus bovino 5 fue inicialmente descrito en Australia a partir de un brote de encefalitis en terneros (Johnston et al., 1962). Posteriormente fue reportado en Europa (Bartha et al., 1969), Canadá (Beck, 1975) Norte América (d'Offay et al., 1993), en Suramérica se ha reportado en Argentina (Carrillo et al., 1983, Riet-Correa et al., 1989, Pidone et al., 1999) y Brasil (Silva et al., 2007; Rissi et al., 2008; Pedraza et al., 2008; Campos et al., 2009).

Inicialmente, se creyó que el virus causante era el Herpesvirus bovino tipo 1 (HVB-1); sin embargo, la presencia únicamente de signos neurológicos hizo sospechar sobre la presencia de una variante de este virus (Weiblen et al., 1989). A través de estudios moleculares, el virus fue clasificado como Herpesvirus bovino 1.3 (Studdert, 1989), posteriormente el comité de taxonomía viral lo clasificaría como un nuevo virus y denominó herpesvirus bovino 5 (HVB-5) (Roizman, 1992).

Estudios de las características antigénicas y moleculares de diferentes aislamientos, han permitido establecer la presencia de 3 subtipos de este virus, HVB-5a, HVB-5b y HVB-5c (Pidone et al., 1999; D'Arce et al 2002). Además, no se ha encontrado asociación entre el subtipo de virus con la sensibilidad en las pruebas de neutralizacion viral (Varela et al., 2010), lo que plantea un desafío futuro en el desarrollo de pruebas que permitan identificar los diferentes subtipos del virus.

El HVB-1 y HVB-5 comparten una homología genética entre el 70 al $85 \%$ (Delhon et al., 2003). Aunque el HVB-5 ha sido asociado con infecciones genitales posteriores a la reactivación de la latencia viral, su principal efecto se observa a nivel neurológico y se considera la segunda causa de encefalitis letal (Sanches et al., 2000). Igualmente, el HVB-5 ha sido detectado en el semen bovino (Gomes et al., 2003) y en fetos abortados (Schudel et al., 1986); aunque no ha sido aislado de embriones y oocitos (Silva-Frade et al., 2010).

En un estudio realizado en Brasil, mediante el uso de técnicas moleculares, a partir de muestras de ganglio trigémino de bovinos de 4 años de edad se encontró una tasa de infección de $82.8 \%$ al HVB-1 y $93.1 \%$ al HVB-5, y una tasa de coinfección a ambos virus de 75.9\% (Campos et al., 2009). En Colombia, en un estudio retrospectivo entre los años 2002 al 2004 a partir de 15 casos ( 10 machos y 5 hembras) con edades entre 6 meses a 5 años de raza cebú y sus cruces diagnosticados con encefalitis no supurativa por parte del Instituto Agropecuario ICA, se detectaron 5 casos como positivos mediante el empleo de técnicas moleculares, lo que confirma su presencia en el país (Pedraza et al., 2010). Una nueva evidencia serológica surgió a partir de 156 muestras de ganado comercial cebú-Brahman provenientes de los Llanos orientales, 91 muestras (58.4\%) fueron positivas a HVB 5, a la vez 88 de estas fueron positivas a HVB-5 y HVB-1 respectivamente (Pedraza et al., 2011). La prueba utilizada fue seroneutralización viral usando las cepas de referencia Cooper para el HVB1 y SV507 para el HVB-5. Llama la atención que estos estudios se han realizado en ganado de carne por lo que se requiere confirmar la presencia en ganado de leche al igual que su presencia en otras regiones ganaderas del país.

En la actualidad, el HVB-5 ha sido reportado como el principal agente responsable de encefalitis no supurativa en bovinos, causante de grandes pérdidas económicas en Europa, USA y América Latina (Cardoso et al., 2010).

En países con alta prevalencia de la enfermedad, se ha utilizado la vacunación mediante el empleo de vacunas convencionales para el HVB-1 con el fin de prevenir los signos de enfermedad desarrollados por el BoHV5 (Campos et al., 2011). Actualmente, no existe una vacuna específica para HVB-5 disponible en el mercado. Por lo anterior, se están desarrollando vacunas recombinantes mediante la remoción de los genes que 
codifican la secuencias de las glicoproteínas gl, gE y la proteína de membrana US9 (BoHV-5 gl/gE/US9) las cuales se encuentran implicadas en la patogenicidad viral (Campos et al., 2011). En países como Brasil, donde los estudios han mostrado una alta prevalencia de la enfermedad, fue ensayada una vacuna recombinante, la cual previno contra la encefalitis, además redujo la eliminación del virus después del desafío con una cepa de campo, sin embargo su eficacia requiere ser probada por estudios a mayor escala (Campos et al., 2011). Otro tipo de vacuna recombinante deficiente para el gen de la timidin kinasa y la glicoproteína E esta siendo probada por otro grupo de investigación en el mismo pais, en los ensayos preliminares, los animales vacunados fueron protegidos y se redujo la eliminación del virus; algunos animales presentaron signos clínicos respiratorios leves y transitorios (Anziliero et al., 2011).

\section{Virus de la Inmunodeficiencia Bovina (VIB)}

Es un miembro del género lentivrus de la familia Retroviridae, junto con el virus maedi-visna (VMV) en ovinos, el virus de la artritis encefalitis caprina (VAEC), el virus de la anemia infecciosa equina (VAIE), el virus de la enfermedad japonesa, el virus de la inmunodeficiencia felina (VIF), el virus de la inmunodeficiencia del simio (VIS) y el virus de la inmunodeficiencia humana (VIH) (Patil et al., 2003).

La primeras evidencias de este virus fueron obtenidas por Van der Mateen (1969) a partir de una vaca Holstein proveniente del estado de Louisiana de 8 años de edad con linfocitosis persistente, la cual inicialmente se sospechó de linfosarcoma bovino. Este animal a la necropsia presento hiperplasia folicular y manguitos perivasculares a nivel cerebral. A partir de este animal se aisló una cepa a la cual se le dio el nombre de R-29 y los estudios por microscopia electrónica presentaron una morfología similar al virus visna (Van den Marteen et al., 1972).

La infección con el VIB no presenta manifestaciones clínicas importantes; sin embargo, en Norte América se ha asociado con una disminución en la producción de leche (McNab et al., 1994) y con una marcada pérdida de peso que termina en infecciones concurrentes severas (Snider et al., 2003). Así mismo, en hatos con alta prevalencia de VIB se ha observado una mayor incidencia de encefalitis y enfermedades bacterianas secundarias (Carpenter et al., 2000). Por otro lado, existe un reporte de un animal con infección experimental de VIB el cual desarrollo un linfosarcoma atípico, aumento transitorio de linfocitos e hiperplasia linfoidea. Estos hallazgos fueron similares a los encontrados en infecciones por otros lentivirus inmunosupresivos (Carpenter et al., 2000). Las infecciones con lentivirus se caracterizan por el establecimiento de persistencia durante toda la vida del individuo una vez ocurre la infección inicial (Flaming et al., 2003).

Los estudios de prevalencia sugieren que el VIB está ampliamente difundido a nivel mundial, se ha reportado en Estados Unidos, Holanda, Suiza, Canadá, Nueva Zelanda, Francia, Gran Bretaña y Australia (Brownlie et al., 1994) En América Latina se tienen reportes en Costa Rica (Hidago et al., 1995) y Venezuela (Brownlie et al., 1994). En este último país, la reactividad serológica se encontró entre $12-66 \%$ y se observó una posible asociación con el "síndrome parapléjico" caracterizado por debilidad en la locomoción, parálisis del tren posterior y muerte después de 72-96 horas después de la recumbencia (Walder et al., 1995). En Brasil, mediante la prueba de Western blot para la detección de la proteína p26 del virus se analizaron 238 sueros provenientes de 6 diferentes fincas encontrando seropositividad de $11.7 \%$ (Meas et al., 2002). En Argentina, el primer reporte de VIB ocurrió en 2008, en 589 muestras de suero analizadas por ELISA provenientes de 9 fincas en 4 provincias, la seropositividad se ubicó entre $2-42 \%$ además se evidenció una posible asociación con el virus de la leucosis bovina (Gonzáles et al., 2008). En Colombia, no se han realizado estudios que determinen la prevalencia de la enfermedad. Por otro lado, no existen reportes de la existencia o el desarrollo de vacunas para el control de este virus.

\section{Rotavirus Bovino}

El rotavirus es un importante patógeno que afecta la productividad de la industria lechera al estar implicado como la principal causa de enteritis en los terneros dentro de las 4 primeras semanas de vida (Saif et al., 1994). Así mismo, este virus tiene impacto en la salud pública ya que se le atribuye la muerte de 611.000 niños cada año especialmente en los países en desarrollo (Parashar et al., 2006). Los primeros reportes del rotavirus se hicieron en la década del 50-60 por microscopia electrónica en tejidos intestinales de un mono en cautiverio, en 1969 se detectaron partículas virales en heces de ganado con diarrea y hasta 1973 se reportaron los primeros casos humanos (Martella et al., 2010). Las pérdidas económicas producidas por el rotavirus bovino se han asociado principalmente a la disminución en la ganancia de peso, costo del tratamiento de los animales enfermos y muerte (Garaicoechea et al., 2006).

Los rotavirus constituyen un género dentro de la familia Reoviridae. El genoma del rotavirus es un ARN de 
doble cadena compuesto de 11 segmentos. El virus tiene forma de rueda y un diámetro entre $70-75 \mathrm{~nm}$ (Martella et al., 2010). Está constituido por una cápside icosahédrica, rodeado por 3 capas sin envoltura. Cada segmento del ARN codifica las diferentes proteínas de virión: 6 proteínas estructurales (VP1, VP2, VP3, VP4, VP6 y VP7) y dependiendo de la cepa 5 o 6 proteínas no estructurales (NSP1-NSP6) (Estes, 2001). Las diferentes variaciones en la secuencias de las proteínas virales ha permitido la clasificación de los rotavirus. Como clasificación general los rotavirus se dividen en 7 grupos (A-G) por las diferencias encontradas en la proteína estructural VP6, siendo el grupo A el más común entre la población. Así mismo, por variaciones en las proteínas de la cápside VP7 (glicoproteína: G) y la VP4 (Proteasa: P) los rotavirus del grupo A se han clasificado en genotipos. Al menos 15 genotipos $G$ correspondientes a la VP7 y 26 genotipos P correspondientes a la VP4 existen en todas las especies de mamíferos. Sin embargo, de todos estos genotipos que existen en la naturaleza solo 8 genotipos de VP7 denominados G (G1, G3, G5, G8, G10 y G15) y 6 genotipos de VP4 denominados P (P1, P5, P11, P14, P17 y $\mathrm{P} 21)$ se han aislado del ganado. Las combinaciones de genotipos G6, G10 y G8 con P5, P11 y P1 se han considerado de importancia epidemiológica en los hatos ganaderos (Garaicoechea et al., 2006).

En la actualidad, la mayoría de países de América Latina realizan esfuerzos para caracterizar el rotavirus bovino mediante el aislamiento viral y la posterior caracterización molecular. En Colombia este patógeno se considera como una de las mayores causas de diarrea en terneros, junto con Cryptosporidium. La prevalencia para rotavirus bovino mediante ELISA de captura a partir de muestras de materia fecal de terneros en la Sabana de Bogotá fue de 26\% (Pardo et al., 2012). A partir de estas muestras Vargas et al. (2011) realizaron la caracterización molecular de los rotavirus que afectan a los terneros en esta zona del país. En el estudio, se evaluaron las regiones que codifican las secuencias VP4 y VP7 del rotavirus bovino. Se encontró que la gran mayoría de las cepas aisladas de rotavirus bovino pertenecen a los genotipos $\mathrm{G}$ más reportados G6 (66\%), G10 (22\%) y G8 (12\%), en cuanto al genotipo $\mathrm{P}$ el $78 \%$ pertenecen al P5 y el $22 \%$ aunque falta establecer a que genotipo $\mathrm{P}$ pertenecen. Según estos resultados, la combinación de genotipos de rotavirus más frecuente en esta zona del país es del G6P5, resultados similares a nivel mundial confirman que esta combinación es la más prevalente en el ganado bovino (Vargas et al, datos no publicados).

La vacunación se ha implementado como medida de control de la enfermedad en algunos hatos ganade- ros. Entre las vacunas disponibles en el mercado se encuentran las vacunas inactivas y las a virus vivo modificado (VLM), las cuales vienen en presentación polivalente junto con otros antígenos virales y bacterianos. En cuanto a la vacuna inactivada es administrada por vía parenteral a las madres para aumentar la inmunidad pasiva y generar mayor protección frente a sus terneros (Parreño et al., 2004). La eficacia de esta vacuna puede estar influenciada por falla en la transferencia pasiva. En cuanto a la vacuna viva modificada, se administra por vía oral a los terneros tan pronto nacen y debe ser administrada con precaución para evitar un bloqueo de la respuesta de anticuerpos maternales (Bellinzoni et al., 1989). Debido al surgimiento de nuevas variantes virales, se requiere la constante genotipificación o secuenciación de las diferentes cepas circulantes para entender la epidemiologia viral dentro de una región y mejorar asi los programas vacunales.

\section{Conclusiones:}

Los agentes virales emergentes y re emergentes constituyen un objeto de atención dentro del desarrollo de la industria bovina mundial. Los virus de la Diarrea Viral Bovina y el Rotavirus Bovino, por su condición genómica ARN, son más propensos a modificaciones, recombinaciones y variaciones dentro de sus secuencias, por tanto, se esta siempre frente a la posibilidad de que surjan variantes virales que generen nuevos cuadros clínicos que no sean controlados por las vacunas desarrolladas. Frente a esta situación, es necesario mantener un sistema de control sobre los virus, basados en su aislamiento y caracterización molecular. Lo anterior brindaría la información necesaria para tomar medidas de control, sean planes de vacunación regional, nacional, programas de erradicación, todo sustentado en el conocimiento al detalle de las cepas actuantes a nivel de campo. Actualmente, para estas dos enfermedades existen vacunas comerciales disponibles; pero se desconoce si las cepas vacunales son las mismas que están circulando en el campo, por tanto se conoce muy poco sobre el espectro de protección. Adicionalmente, las vacunas tradicionales ocasionan problemas colaterales asociados con su administración. Estos aspectos obligan al desarrollo de nuevas alternativas como las vacunas recombinantes. Otros virus como el Herpesvirus bovino 5 y el virus de la inmunodeficiencia bovina, han surgido como agentes protagonistas en los sistemas de producción bovina; particularmente en países de la región suramericana, en donde generan altas pérdidas económicas. En Colombia, desconocemos el estatus sanitario para estos virus y es urgente realizar estudios de prevalencia que confirmen su presencia, establecer sistemas de 
diagnostico y aislamiento y determinar su implicación en las pérdidas económicas para nuestra ganadería.

\section{Referencias}

Anziliero D, Santos CMB, Brum MCS, Weiblen R, Chowdhury SI, Flores EFA recombinant bovine herpesvirus 5 defective in thymidine kinase andglycoprotein $\mathrm{E}$ is immunogenic for calves and confers protection upon homologous challenge and BoHV-1 challenge. Vet Microbiol 2011; 154: 14-22.

Bellinzoni R, Blackhall J, Baro N, Auza N, Mattion N. Efficacy of an inactivated oil adjuvanted rotavirus vaccine in the control of calf diaorrhea in beef herds in Argentina. Vaccine 1989; 7: 263268.

Borda A. Diarrea viral bovina en terneros y terneras procedentes de Holanda. Tesis de pregrado, Facultad de Medicina Veterinaria, Universidad Nacional de Colombia, Bogotá, 1975.

Brock K. The many faces of bovine viral diarrhea virus. Vet Clin Food Anim 2004; 20: 1-3.

Brownlie J, Collins M, Eaton PH. 1994. Bovine immunodeficiencylike virus a potential cause of disease in cattle? Vet Rec 289291

Campos FS, Franco AC, Hübner SO, Oliveira MT, Silva AD, Esteves PA, Roehe PM, Rijsewijk FAM. High prevalence of coinfections with bovine herpesvirus 1 and 5 found in cattle in southern Brazil. Vet Microbiol 2009; 139: 67-73

Campos FS, Dezen D, Antunes DA, Santos HF, Arantes TS, Cenci A, Gomes F, Lima FES, Brito WMED, Filho HCK, Batista HBCR, Spilki FR, Franco AC, Rijsewijk FAM, Roehe PM. Efficacy of an inactivated, recombinant bovine herpesvirus type 5 (BoHV-5) vaccine. Vet Microbiol 2011; 48: 18-26

Cardoso TC, Gomes DE, Ferrari HF, Silva-Frade C, Rosa ACG, Andrade AL, Luvizotto MCR. A novel in situ polymerase chain reaction hybridization assay for the direct detection of bovine herpesvirus type 5 in formalin-fixed, paraffin-embedded tissues. J Virol Method 2010; 163 509-512

Carpenter S,Vaughn E,Yang J, Baccam P. Antigenic and genetic stability of bovine immunodeficiency virus during the long term persistence in cattle experimentally infected with the VIB R29 isolate. J Gen virol 2000; 81:1463

Carrillo BJ, Ambrogi A, Schudel AA, Vazquez M, Dahme R, Popischil A. Meningo-encephalitis caused by IBR virus in calves in Argentina. Zbl Vet Med B 1983; 30: 327-332

Casaubon J, Vogt HR, Stalder H, Hug C, Ryser-Degiorgis MP. Bovine viral diarrhea virus in free-ranging wild ruminants in Switzerland: low prevalence of infection despite regular interactions with domestic livestock. BMC Vet Res 2012, 8:204

Castañeda V. Implementación de la técnica de inmunohistoquímica para la detección del VDVB utilizando Acs monoclonales 15c5 en tejidos fijados con formol. Tesis de pregrado, Facultad de Medicina Veterinaria y de Zootecnia, Universidad Nacional de Colombia, Bogotá ,2004

D'Arce RCF, Almeida RS, Silva TC, Franco AC, Spilki FR, Roehe PM, Arns CW. Restriction endonuclease and monoclonal antibody analysis of Brazilian isolates of bovine herpesviruses types 1 and 5. Vet Microbiol. 2002; 88: 315-324.

Delhon G, Moraes MP, Lu Z, Afonso CL, Flores EF, Weiblen R, Kutish GF, Rock, DL. 2003. Genome of bovine herpesvirus 5. J Virol. 77, 10339-10347.

Estes MK, 2001. Rotaviruses and their replication. In: Knipe DM, Howley PM, Griffin DE, Lamb RA, Martin MA, Roizman B. Strais, S.E. (Eds.), Fields Virology. 4th ed. Lipincott William and Wilkins, Philadelphia, Pa, pp. 1747-1785.

FAO. Perspectivas a plazo medio de los productos básicos agrícolas. Proyecciones al año 2010. Roma, 2004

Flaming K, Van der maaten M, Whetstone C, Carpenter S, Frank D. Roth J. Effect of bovine immunodeficiency-like virus infection on immune function in experimentally infected cattle. Vet immunol immunopathol, 1993 (2):91-105

Flores EF, Ridpath JF, Weiblen R, et al. Phylogenetic analysis of Brazilian bovine viral diarrhea virus type 2 (BVDV-2) isolates: evidence for a subgenotype within BVDV-2. Virus Res 2002;87(1):51-60.

Fourichon C, Beaudeau F, Bareille N, Seegers H. Quantification of economic losses consecutive to infection of a dairy herd with Bovine Viral Diarrhea Virus. Prev Vet Med 2005; 72: 177-81.

Galeto A. El mercado Internacional de Leche y productos lácteos: Situación actual y factores que explican su comportamiento. En: XXI Curso Internacional de lechería para profesionales de América Latina. Mayo 2008 Argentina.

Gallego MI, Cortes E, Galvis ALH, Agudelo DL. Diarrea viral bovina en Colombia. Analac, 1987; 70: 10-13.

Garaicoechea L, Bok K, Jones L, Combessies G, Odeon A, Fernandez F, Parreno V. Molecular characterization of bovine rotavirus circulating in beef and dairy herds in Argentina during a 10 year period (1994-2003). Vet microbiol 2006; 118: 1-11.

Gomes LI, Rocha MA, Souza JG, Costa EA, Barbosa-Stancioli EF. Bovine Herpesvirus 5 (BoHV-5) in bull semen: amplification and sequence analysis of the US4 gene. Vet Res Commun 2003;27:495-504.

González ET, Licursi M, Vila Roza V, Bonzo E, Mortola E, Frossard JP. Venables C. Evidence of bovine immunodeficiency virus (BIV) infection:Serological survey in Argentina. Res Vet Sci 2008; 85: 353-358

Gunn G, Saatkamp H, Humphry R, Stot A. Assesing economic and social pressure for the control of BVDV. Prev Vet Med 2005; 72: $149-162$.

Hamers C, Dehan P, Couvreur B, Letellier C, Pastoret P. Diversity among Bovine Pestiviruses. Vet J. 2001; 161: 112-22.

Hidago G, Flores M, Bonilla A. Detection and isolation of bovine immunodeficiency-like virus (BIV) in dairy herds of Costa Rica. J Vet Med B. 1995; 42 : 155-161.

Heuer C, Healy A, Zerbini C. Economic Effects of Exposure to Bovine Viral Diarrhea Virus on Dairy Herds in New Zealand. J Dairy Sci. 2007; 90:5428-5438 
Houe $\mathrm{H}$. Epidemiological features and economical importance of bovine virus diarrhoea virus (BVDV) infections. Vet Microbiol.1999; 64 89-107

Johnston LAY, Simmons GC, MC Gavin MD. A viral meningo-encephalitis in calves. Austral Vet J. 1962; 38: 207-215.

Jones LR, Zandomenib R, Weber EL. Genetic typing of bovine viral diarrhea virus isolates from Argentina. Vet Microbiol 2001; 81: $367-375$

Lee KM, Gillespie JH. Propagation of virus diarrhea virus of cattle in tissue culture. Am J Vet Res 1957;18:952-953.

Lindberg A, Brownlie J, Gunn GJ, et al. The control of bovine viral diarrhea virus in Europe: today and in the future. Rev Sci Tech 2006;25(3):961-979.

Liu L, Xia H, Wahlberg N, Belak S, Baule C. Phylogeny, classification and evolutionary insights into pestivirus. Virology 2009, 385; 351-357.

Meas S, Ruas FJ, Usui, T, Teraoka, Mulenga A, Chang KS, Masuda, A Madruga CR, Ohashi K, Onuma M. Seroprevalence and molecular evidence for the presence of bovine immunodeficiency virus in Brazilian cattle. Jpn J Vet Res. 2002; 50 (1) : 9-16

McNab WB, Jacobs RM, Smith HE. A serological survey for bovine immunodeficiency-like virus in Ontario dairy cattle and associations between test results, production records and management practices. Can J Vet Res. 1994; 58:36-41.

Martella V, Bányai K, Matthijnssens J, Buonavoglia C, Ciarlet M. Zoonotic aspects of rotaviruses. Vet Microbiol 2010; 140:246255

Mettenleiter T, Sobrino F, editors. Animal Viruses: Molecular Biology. Madrid: Caister Academic Press; 2008.

Nobiron I, Thompson I, Browlie J, Collins M. DNA vaccination against Bovine Viral Diarrhea Virus induces humoral and cellular responses in cattle with evidence for protection against viral challenge. Vaccine 2003; 21: 2082-92.

Moennig V. Prolonged persistence of cytopathogenic bovine viral diarrhea virus in a persistently viremic cattle. J Vet Med 1993; 40: $371-377$

Olafson P, McCallum A, Fox F. An apparently new transmissible disease of cattle. Cornell Vet. 1946;36:205-213.

Ortega A. Posicionamiento socioeconómico de la leche. En: Buenas prácticas de producción primaria de leche. Fondo editorial biogénesis, 2007.

Parashar UD, Gibson CJ, Bresse JS, Glass RI. Rotavirus and severe childhood diarrhea. Emerg Infect Dis. 2006; 12: 304-306

Parreño V, Bejar C, Vagnozzi A, Barrandeguy M, Constatini V. Modulation by calostrum acquired maternal maternal antibodies of systemic and mucosal antibody responses to rotavirus in calves experimentally challenged with bovine rotavirus. Vet immunol immunopathol 2004; 100: 7-24

Patil SS, Pattnaik B, Mishra N, Banumathi N, Dubey R, Pradhan HK. Detection of proviral genomic sequence of bovine immunodeciciency virus in Indian cattle. Current Sci 2003; 84, 4:563-566.
Pedraza FJ, Schildb AL Alessi AC Descripción inmunohistoquímica de la encefalitis en bovinos brasileños naturalmente infectados con el herpesvirus bovino tipo 5 (HVB-5). Arch Med Vet 2008; 40: $69-75$

Peterhans E, Bachofen C, Stalder H, Schweizer M. Cytopathic bovine viral diarrhea viruses (BVDV):emerging pestiviruses doomed to extinction. Vet Res. 2010; 41:44

Pidone CL, Galosi CM, Echeverria MG, Nosetto EO, Etcheverrigaray ME. Restriction Endonuclease Analysis of BHV-1 and BHV-5 Strains Isolated in Argentina. J Vet Med B Infect Dis Vet Public Health 1999; 46: 453-456.

Proexport, El sector Lácteo en Colombia, 2011; [fecha de acceso $\quad 08 / 09 / 11$ http://www.proexport.com.co/sites/default/ files/Colombia_Pa\%C3\%ADs_de_Oportunidades_Septiembre_2011.pdf

Ridpath JF Bovine Viral Diarrhea Virus: Global Status. Vet Clin Food Anim 2010; 26:105-121

Riet-Correa E, Vidor T, Schild AL, Méndez MC. Meningoencefalite e necrose do córtex cerebral em bovinos causada por herpesvirus bovino-1. Pesqui Vet Bras 1989; 9: 13-16.

Rissi DR, Pierezan F, Sá e Silva M, Flores EF. Lombardo de Barros, CS. Neurological disease in cattle in southern Brazil associated with Bovine herpesvirus infection. J Vet Diag Invest. 2008; 20: 346-349.

Rodas JD. Virus emergentes y herramientas para su estudio molecular. Rev Col Cienc Pec. 2002; 15(3):342-355.

Roizman B. The family Herpesviridie: An update. Arch Virol 1992; 123: 43-445.

Saif LJ, Rosen B, Parwani A. 1994. Animal Rotaviruses. In: Kapikian, A. (E d.), Viral Infections of the Gastrointestinal Tract. Marcel Dekker, Inc, New York, pp. 279-367.

Sanches AWD, Langohr IM, Stigger AL, Barros CSL. Doenc $\square$ s do sistema nervosa central em bovinos no Sul do Brasil. Diseases of the central nervous system in cattle in southern Brazil. Pesqui Vet Bras 2000;20:113-118.

Snider 3rd TG, Coats KS, Storts RW, Graves KF, Cooper CR, Hoyt PG, Luther DG, Jenny BF. Natural bovine lentivirus type 1 infection in Holstein dairy cattle. II. Lymphoid tissue lesions. Comp Immunol Microbiol Infect Dis. 2003; 26: 1-15.

Stahl K, Kampa J, Baule C, et al. Molecular epidemiology of bovine viral diarrhoea during the final phase of the Swedish BVD-eradication programme. Prev Vet Med 2005;72(1-2):103-108 .

Schudel AA, Carrilo BJ, Wyler R, Metzler AE. Infections of calves with antigenic variants of bovine herpesvirus 1 (BHV-1) and neurological disease. J Vet Med 1986;33:303-310.

Silva MS, Brum MCS, Weiblen R, Flores EF. Identificação ediferenciação de herpesvírus bovino tipos 1 e 5 isolados de amostras clínicas no Centro-Sul do Brasil, Argentina e Uruguai (19872006). Pesqui Vet Bras. 2007; 27: 403-408.

Silva-Frade C, Martins Jr. A, Borsanelli AC, Cardoso TC. Effects of bovine Herpesvirus Type 5 on development of in vitro-produced bovine embryos. Theriogenology 2010; 73: 324-331 
Studdert MJ. Bovine encephalitis herpesvirus. Vet Rec 1989; 125: 584.

Vargas DS, Vera V, Jaime J. Perspectivas en el control del virus de la Diarrea Viral Bovina. Rev Colomb Cienc Pecu 2009; 22:677688

Uttenthal A, Stadejek T, Nylin B. Genetic diversity of bovine viral diarrhoea viruses (BVDV) in Denmark during a 10-year eradication period. APMIS 2005;113(7-8):536-41

Valle P, Skjerve E, Wayne S, Larsen R, Nyberg O. Ten years of BVDV control in Norway: A cost benefits analysis. Prev Vet Med 2005; $72: 189$

Walsh SW, Williams EJ, Evans ACO. A review of the causes of poor fertility in high milk producing dairy cows. Anim Reprod Sci. 2011; 123: 127-138

Van Der Maarten MJ, Bootle AD, Seger CL. Isolation of a virus from cattle with persistent lymphocytosis. J Natl Canc Res Inst 1972; 49:1649-1657
Varela APM, Holz CL, Cibulski SP, Teixeira TF, Antunes DA. Franco AC, Roehe LR, Oliveira MT, Campos FS, Dezen D, Cenci A, Brito WD, Roehe PM. Neutralizing antibodies to bovine herpesvirus types 1 (BoHV-1) and 5 (BoHV-5) and its subtypes. Vet Microbiol 2010; 142: 254-260

Vargas DS. Construcción de un adenovirus recombinante que exprese proteínas inmunogénicas del Virus de la Diarrea Viral Bovina. Tesis de maestría. Facultad de Medicina Veterinaria y de zootecnia. Universidad Nacional de Colombia 2010.

Vargas DS, Jaime J, Vera VJ. Perspectivas para el control del Virus de la Diarrea Viral Bovina (BVDV). Rev Colomb Cienc Pecu 2009; 22:677-688

Walder R, Kalvatchev Z, Tobin GJ, Barrios MN, Garzaro DJ, Gonda MA. Res Virol 1995; 146:313-323

Weiblen R, Barros CSL, Canabarro TF. Bovine Meningoencephalitis from IBR virus. Vet Rec 1989; 124: 666-667. 